\title{
Worth a thousand words: Connecting tourism operators with climate change through visualisation techniques
}

\author{
$\underline{\text { L. Lim-Camacho }}^{\text {a }}$ and P. Ashworth ${ }^{a}$ \\ ${ }^{a}$ Science into Society, CSIRO Earth Science and Resource Engineering, Pullenvale, Queensland Australia \\ Email: lilly.lim-camacho@csiro.au
}

\begin{abstract}
The old saying "a picture paints a thousand words" has never been more appropriate when discussing the issue of communicating climate scenarios. Our research demonstrates the benefits of using imagery creatively to effectively communicate large amounts of scientific information in a powerful, easy to understand format for tourism operators in Queensland's Sunshine Coast. Globally, tourism has been identified as an industry in the 'climate danger zone', where risks are significant but many operators remain unprepared. Tourism is Australia's second-largest export earner, yet the industry is comprised primarily of small businesses managed by individuals with limited business experience and training. The combination of a lack of awareness, capability and preparation for potential climate risks coupled with poor engagement with adaptation options, places one of Australia's most valuable assets in a vulnerable situation.
\end{abstract}

Using a multi-disciplinary approach, the research combined projections from climate scientists with tourism operator perceptions of climate change and adaptation, gathered through an engagement process consisting of interviews and workshops conducted over eight months. The process involved five stages of engagement and consultation with industry prior to the release of a final product. The result is a visual and interactive PDF used to communicate the scenarios across the industry in the designated region, wherein users can selfnavigate at their own pace. The tool itself has initially been well received when it was road tested with tourism operators with only minor suggestions for improvements.

As a result of the positive response it appears there are multiple additional applications either used across different industry sectors or across various climatic regions. For example, it has been suggested that such a process could be used to develop a tool for different regions of Australia that various industry and small business operators working in that area could use to help inform them about likely climate impacts and therefore plan accordingly. In addition, the process of developing the tool has encouraged climate scientists to become more aware of end-user needs and how to adapt their science to improve its relevance across society. The tool itself provides a mechanism that is a low cost way of encouraging ongoing climate action.

Keywords: climate change scenarios, communication, end-users, visualisation 
Lim-Camacho \& Ashworth, Worth a thousand words: Connecting tourism operators with climate change through visualisation techniques

\section{INTRODUCTION}

Communicating climate change is often referred to as a complex task that requires an integrated approach (Nerlich et al 2009; Devine-Wright, 2013). It is widely recognized as challenging (Peattie et al., 2009 Pidgeon, 2012), in particular because of its inherent uncertainties and risk associations (Budescu et al., 2012). Climate change has been identified as one of a number of scientific issues that needs 'better marketing', where the goal is to encourage public open-mindedness for consideration of scientific information (Kahan, 2010). De Freitas (2003) states that it is important for climatologists to translate their work into simple language, however past experience has demonstrated that climate science 'translation' is not a simple task.

The tourism industry, having strong connections to climate and the environment, is considered as one that is highly vulnerable to changes in the natural environment (KPMG International, 2008). The risk and uncertainty of climate change poses a substantial threat to tourism operators across Australia. However, there is little evidence of long-term strategic planning in anticipation of climate change amongst tourism operators (Scott et al., 2009) with most adaptation occurring in light of compliance to standard regulations (Bleda \& Shackley, 2008). As a result it appears that the majority of tourism business operators are unaware of, and so unprepared for, the climate risks they face.

This is in spite of tourism being a vital industry for Australia - generating approximately US\$95 billion in spending and contributing $2.6 \%$ of Australia's total GDP (DRET, 2012). As such, it makes sense to engage tourism operators in climate change adaptation and mitigation to help maintain their economic viability and competitiveness (Cabrini, 2010). Becken (2005) highlights this point in stating that there is a need for tourism-specific climate change information, including its impacts as well as adaptation and mitigation options for operators.

As with the general public, tourism operators have limited knowledge of the science of climate change, and can be confused, but also concerned, about the impacts of change globally, on their region, the tourism industry and their business. Early research in this space has demonstrated that there is benefit in taking tourism operators through a process of learning prior to asking them to take action (Thomas et al., 2010). This is crucial, as this process of engagement also identified that tourism operators who acknowledge the reality of climate change are more likely to take action and convert potential risks into opportunities.

As such with a predominantly uninformed community, there is a need to find alternative and engaging methods to inform and educate tourism operators of the potential impacts of climate change. Previous studies (Thomas et al., 2010) suggest that to maximise impact, climate change information needs to be delivered to tourism operators in a manner that is accessible, but also convincing and catering to specific needs. More broadly, the need for tailored climate information is also relevant to many other sectors, although work in this field is still limited (Moser, 2010; Nursery-Bray et al., 2012; Peattie et al., 2009). Building on work initiated by Thomas, et al. (2010), this study identifies an approach to effectively communicate climate change information to tourism operators through the use of a visualisation tool.

\section{RATIONALE}

It has been well documented that the scientific understanding of risk and uncertainty can vary greatly from the understanding of the public (Moss \& Schneider, 2000; Leiserowitz, 2005). This has generated concerns about the best way to communicate issues such as climate change, where multiple decisions need to be made before all of the associated risks and uncertainties can be resolved (CCSP, 2009). Successful responses to climate change are likely to be those that are supported by decisions informed by the latest climate science (Sarewitz \& Pielke JR, 1999). However, for many, a gap remains between the information provided and how it translates into real life (Nerlich, Koteyko, \& Brown, 2010). The uncertainty associated with a range of climate scenarios can be difficult for lay persons to understand, particularly because of the complex biophysical and human interactions, which have an impact on how adaptation occurs (CCSP, 2009).

Over time, the results of the interactions between biophysical and anthropogenic actions have resulted in a number of climate projection scenarios. However, climate projections scenarios, generated through global climate models (GCMs) are often presented with a focus on climate variables rather than local conditions, as adding contextual detail often creates another layer of uncertainty. Yet, local context is crucial in allowing end-users to identify with the changes that are projected for their region (Devine-Wright, 2013). Therefore, it is important to find ways to translate the global or continental-scale climate projection scenarios into ones that can be used at a regional scale to enable local level planning for adaptation and mitigation.

Various groups have developed a range of communication tools to translate the climate science and enhance its applicability. For example, the Department of Environment and Primary Industries, Victoria uses 
Lim-Camacho \& Ashworth, Worth a thousand words: Connecting tourism operators with climate change through visualisation techniques

Climatedogs (http://www.dpi.vic.gov.au/?a=51059) - an animation directed at farmers to describe the four global climate processes that affect Victorian agricultural seasons. As well as providing information, these types of tools appeal more to the emotive side of the end user and go beyond the more traditional websites that are filled with climate science facts and maps that indicate the suggested impacts of climate change (see for example, http://earthobservatory.nasa.gov/).

The value of visual communication tools for climate information was confirmed in a survey $(n=1,602)$ of the Australian general public in 2010, where the major preferred sources of climate change information were visual (Ashworth et al., 2010). However, visualising future climate change impacts, based on the science can be difficult because of the lengthy timelines involved in the scenarios. And yet, many in the tourism industry are being encouraged to consider both mitigation and adaptation actions now because of the implications for their businesses if left unaddressed. Therefore it was felt important to use visual imagery in ways that would encourage positive engagement rather than negative messaging that has been show to lead to public disengagement with the issue (Manzo, 2010). Therefore, the aims of this research were to develop and evaluate the effectiveness of a visual tool that informed tourism operators of the potential risks that a changing climate may bring for the future as well as to encourage them to consider the implications for their business, and what they could do to mitigate and/or adapt to these risks.

\section{THE TOOL}

Using a multi-disciplinary approach, the tool was developed by combining projections from climate scientists with tourism operator perceptions of climate change and adaptation, gathered through an engagement process consisting of interviews and workshops conducted over eight months. The process involved five stages of engagement and consultation with industry prior to the release of a final product. The tool is designed to be accessed online in Adobe's Portable Document Format (PDF), which can be saved by the user for future use.

The Sunshine Coast Climate Futures tool has three sections; an Introduction, which provides an overview to the tool, instructions on how to use it and background information on the scenarios; the Scenarios, which depict the plausible Climate Futures followed by a summary; and the Climate Futures Plan, which encourages the user to start an adaptation plan for the changes presented in the tool. This paper focuses on the Introduction and Scenarios sections of the tool which aims to effectively communicate potential climate change for the region.

\subsection{Introduction}

The Introduction (Fig. 1) starts with a position on climate change and how tourism operators need to take stock and prepare. It explains the rationale behind the tool and guides the audience on its use. The section also provides additional information on the science behind Climate Futures, how climate projections for this tool were developed using the Climate Futures Framework (Clarke et al. 2011), as well as guidelines on icons and what users should expect. Lastly, document information, including acknowledgements and citation information, is provided in a separate tab.

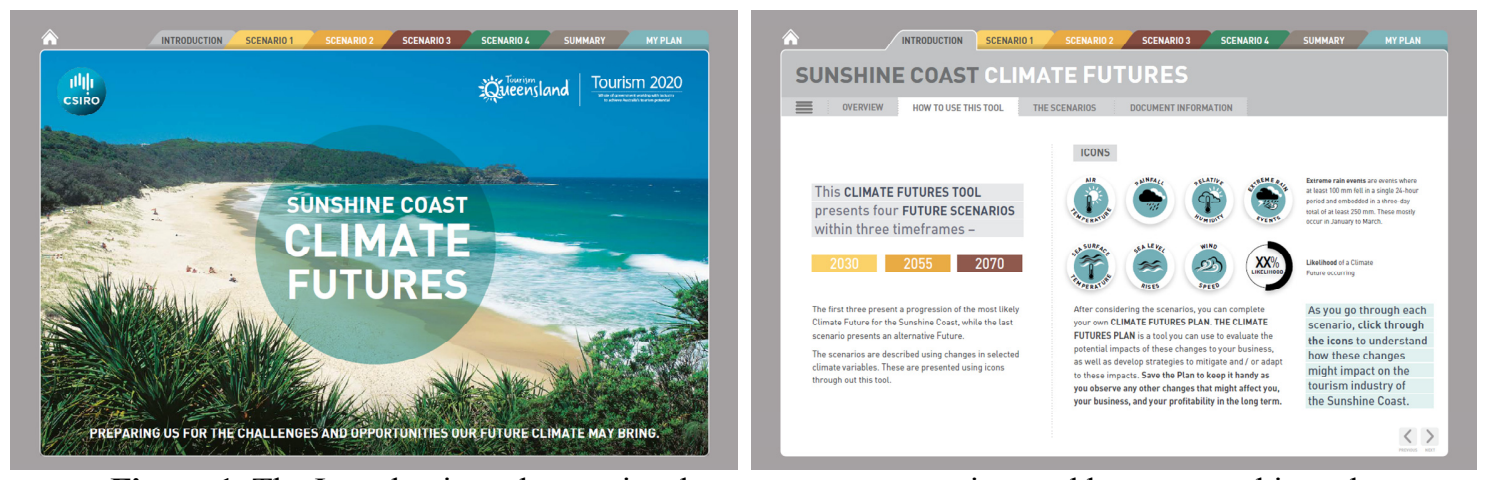

Figure 1. The Introduction tab contains the cover page, overview and how to use this tool

\subsection{Climate Futures scenarios}

This section of the tool features the four plausible Climate Futures scenarios identified for the Sunshine Coast using CSIRO's Climate Futures Framework (Clarke et al. 2011). Each Climate Future is presented through multiple information layers, utilising images, icons, colour and qualitative descriptions supported by insights from tourism operators delivered through quotes (Fig. 2). Images were sourced mostly from the Tourism 
Lim-Camacho \& Ashworth, Worth a thousand words: Connecting tourism operators with climate change through visualisation techniques

Queensland image database, supplemented by images from CSIRO's Science Image database and online stock photos. The Climate Futures are also presented with a likelihood of a Future occurring, shown in the upper right hand corner of the screen. Users navigate through the scenario by clicking on the climate variable icons.

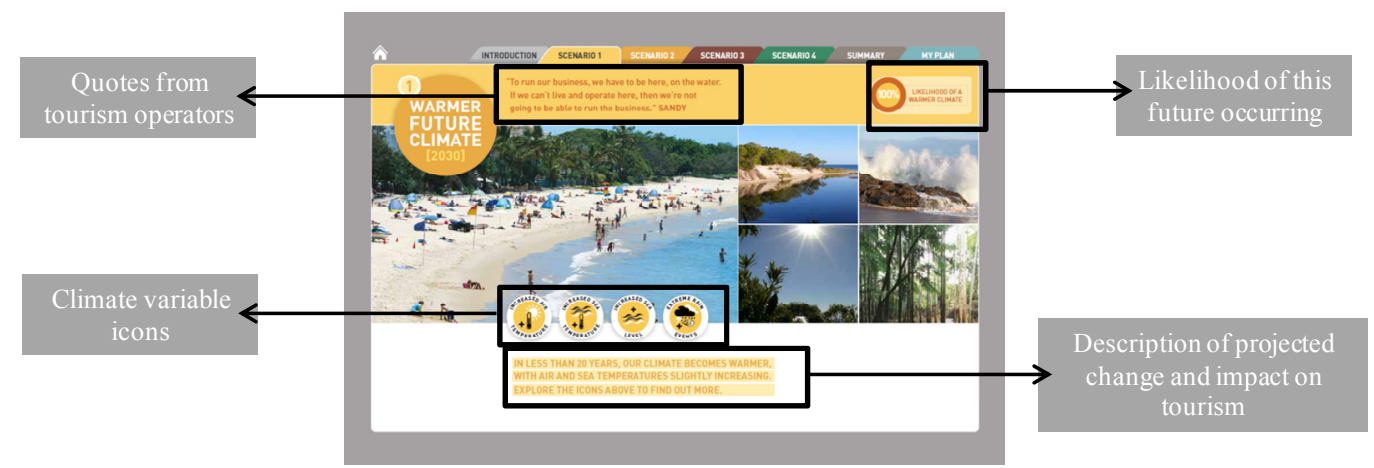

Figure 2. 2030 Warmer Climate Future: Features of the tool

Scenarios are presented in a highly visual manner, communicating potential changes through images of various tourism facets, as well as a qualitative description of what the changes can mean for the industry. Users can select a climate variable that they are interested in, with information on the projected changes as well as potential impacts on the tourism industry as identified by tourism operators.

The first future is a Warmer Climate Future for 2030, characterised by a sunny environment not too different from the current climate in the Sunshine Coast. The 2030 Warmer Climate Future features changes to four climate variables (Fig. 2). The second future is a Hotter and Drier Future Climate for 2055 (Fig. 3), illustrated by images showing a drying trend, as well as erosions and potential flooding. The 2055 Climate Future features changes to six climate variables. The third future is a Hotter and Much Drier Future Climate for 2070 (Fig. 4), characterised by droughts and more extreme weather patterns. The 2070 Climate Future also features changes to six climate variables.

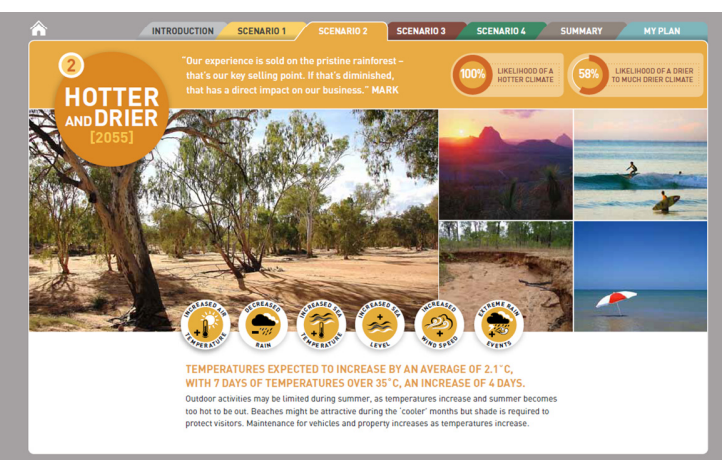

Figure 3. 2055 Hotter and Drier

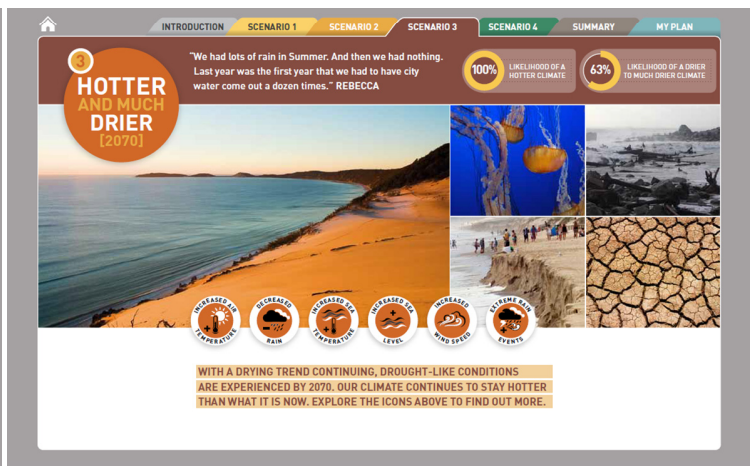

Figure 4. 2070 Hotter and Much Drier

The fourth future scenario presented is an alternative for 2070 - Hotter and Much Wetter (Fig. 5). It is characterised by images showing a tropical feel, alongside cyclonic events and wet weather. The Hotter and Much Wetter Climate Future has a low likelihood, nonetheless it is a plausible future that warrants consideration. This scenario is important in highlighting the meaning of uncertainty, and acknowledges that there may be alternate futures to be considered. It was very effective in addressing contrasting opinions, especially those generated by climate variability.

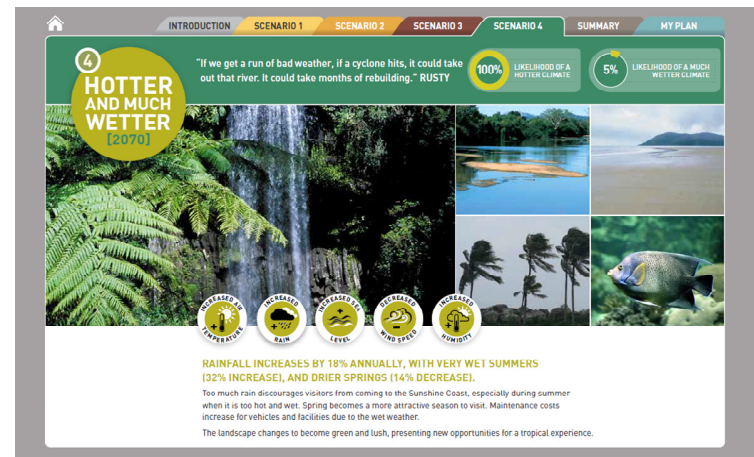

Figure 5. A Hotter and Much Wetter 2070

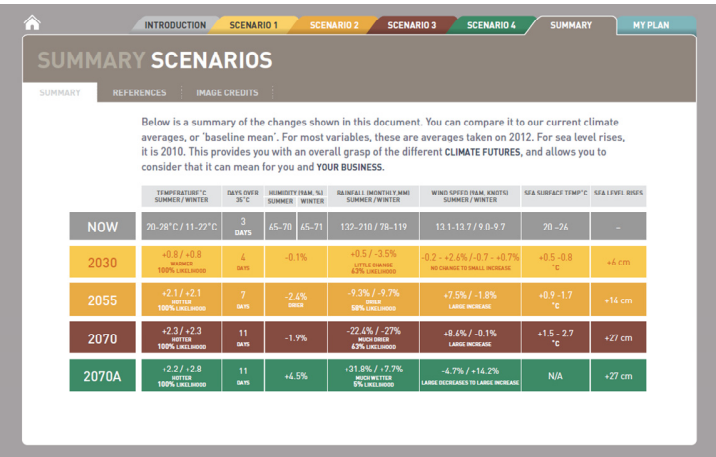

Figure 6. Summary of Climate Future changes 
Lim-Camacho \& Ashworth, Worth a thousand words: Connecting tourism operators with climate change through visualisation techniques

Users are then given a summary of the changes (Fig. 6) across all scenarios presented in the tool, compared against current-climategeophysical variable baseline means presented for 2012 (2010 for sea level rise). The table presents changes against the current climate, which allows end users to contextualise change presented in numerical values against historical data. This completes the communication aspect of the Sunshine Coast Climate Futures tool, aiming to equip tourism operators with enough information to consider the impacts of climate change on their own business operations.

\section{EVALUATING THE TOOL}

To ensure that the Sunshine Coast Climate Futures tool met the needs of its target audience, a review of its draft form was conducted through in-depth interviews with a sample of tourism operators $(n=11)$ comprising of some operators who participated in earlier interviews as well as others who were contacted for the first time. Operators were initially asked to look through the tool and use it instinctively, without any guidance from the interviewer. This allowed for the assessment of general useability and navigation, and identified areas where confusion arose. Following this, operators were asked to describe their initial reaction to the draft tool and its overall impact. Discussion was then directed towards the look and feel, language and content, and whether or not the tool met its desired objectives. Finally, tourism operators were asked to provide suggestions on the ideal channels through which the Climate Futures tool could be distributed. Where possible, the suggestions provided by the tourism operators were incorporated into the final Sunshine Coast Climate Futures tool.

\subsection{Look and feel}

In designing the Climate Futures tool it was important to consider the different learning styles that people have in order to assimilate information provided to them. It was important that the information was conveyed in a manner that brings together abstract concepts with everyday experiences, making future climate change scenarios more locally and individually relevant (Nicholson-Cole, 2005). The use of visualisations through a combination of images, icons, colour and text were utilised to achieve this objective.

Overall, the initial reaction to the Climate Futures tool was that it looked good, and that the images and graphics used had significant impact. In particular, the images used for the scenarios gave the users a feeling of what their surroundings will be like in the future. For most scenarios, it was felt there was a good balance of both hinterland and coastal aspects of the Sunshine Coast, which was important in engaging the different types of tourism operators in the Sunshine Coast region as operators have strong place attachment (DevineWright, 2013; Scannell \& Gifford, 2013). The 2030 scenario however lacked some of this balance, and a recommendation was made to replace a coastal image with one of the hinterland.

In addition, tourism operators who reviewed the tool felt that the presentation was uncluttered and allowed them to focus on the information that was necessary, especially for the scenarios. There was a good balance between content and imagery for the scenarios, which allowed them to understand what the different Climate Futures entailed without having to spend too much time reading.

\subsection{Navigation and useability}

A key criterion in designing this communication tool was that it needed to be intuitive. As such, the Climate Futures tool was designed so that the information could be accessed in various ways. Users can self-select the information that they want to access by using its interactive features, by clicking through tabs and icons. They are allowed to pick a scenario they are most interested in, rather than be directed towards one that is most likely to occur. At the same time, users can also scroll through the document and be able to access all the information in this manner. The interview participants verified the importance of having these options, as they used different ways to go through the tool. In addition, operators suggested minor useability changes that increased the ease by which information is absorbed. It was important to identify these improvements, as often subtle changes can enable users to continue using the tool with as few barriers as possible.

\subsection{Language and content}

Tourism operators who reviewed the Climate Futures tool felt that the language used in the tool was easily understood and accessible, allowing them to understand its key messages. The way the Climate Futures Scenarios were presented, using images and combining quantitative data (scientific projections) with qualitative input (tourism impacts) delivered the message that the information is factual and believable. This is an important achievement given that there were some operators in the group interviewed who felt some level of scepticism when it comes to the 'reality' of climate change. 
Lim-Camacho \& Ashworth, Worth a thousand words: Connecting tourism operators with climate change through visualisation techniques

However, in the draft tool, the term 'storylines' was used in place of 'scenarios'. Most interview participants felt that the term suggested fiction, and therefore something that is not scientific in nature. Others also thought that 'storylines' referred to case studies of tourism operators who have made changes in response to climate change, in essence, someone 'telling a story'. As a result, this was changed to the term 'scenarios', which was used freely and without prompting by the tourism operators interviewed.

Another important achievement is that through the range of Climate Futures Scenarios, especially through the inclusion of an alternative scenario (2070 Hotter and Much Wetter), users felt that they weren't being forced to believe that there is only one possible future. The presentation of alternative, but plausible, futures gave them the impression that they are able to make an informed decision. Having the likelihood of each scenario also allowed them to make rational fact-based decisions on which climate future is more likely to occur.

As expected, some considered the 2055 and 2070 timelines too far off for them to consider. However, the need to project to the long term was understood in that shorter timeframes will only reflect weather variability, while longer timeframes will more accurately reflect climate changes. This illustrates a good level of understanding of the underpinnings of climate change - the difference between weather and climate.

\section{CONCLUSION}

Like many Australians, tourism operators have a limited knowledge of the science of climate change, and can be confused, but also concerned, about the impacts of change globally, on the tourism industry, their region, and their business. Communicating climate change information should be a learning process that is tailormade to the needs of its target audience (CCSP, 2009). It is important to understand the type of language that needs to be used, and the extent of information that needs to be provided to operators in order to assimilate information on climate change. For the Sunshine Coast tourism operators, it was important that the information was delivered in an objective manner, and in a way that allowed them to shape their own opinion and therefore make their own decisions.

The Climate Futures tool was successful in communicating the issue of climate change because it presented alternative scenarios. These alternative scenarios implied that tourism operators are given the choice, but combined with the likelihood percentages, rational thought leads them to choose the Climate Future that science has identified to be most likely. This insight leads us to conclude that presenting only one scenario, even if it is the most likely, will not be as effective as presenting a range of scenarios and allowing users to make their own decisions.

In addition, presenting scenarios using images that tourism operators were familiar with and showcasing specific locales in the Sunshine Coast, enabled the end-users to understand the meaning behind climate projections. Presenting an image that suggested a warm day along with a qualitative description was more effective than simply presenting a projected change in temperatures presented numerically. Showcasing the impact to their immediate environment was important for tourism operators because of the value of the local environment to the industry and individual businesses. This paper highlights the applications of visualisation techniques and scenario based approaches to communicating regional impacts of climate change to a specific target audience, the Sunshine Coast tourism industry.

By creating a tailor-made communication strategy, taking into account the information and communication needs of the target audience, we were able to develop a decision-making tool that informs its users of potential impacts of different climate change scenarios, as well as provide them with the tools to begin the adaptation decision-making process. The key features of this tool include rich visualisation and interactivity, allowing end-users to grasp the reality of potential climate futures by linking it to their region and utilising place attachment. At the back end, the development of the tool is based on harnessing existing levels of understanding of climate change by end-users, and targeting information provisions towards gaps through their own language.

Due to the tool's preliminary demonstrated effectiveness, it is recommended that it be applied and extended to other industries and end-users in order to test the applicability in other contexts. This is currently being undertaken in a project aimed at providing information packages to natural resource management (NRM) groups Australia-wide. This project, which is a collaboration between CSIRO and Griffith University (funded by the Australian Federal Government's Clean Energy Future program), is developing multiple tailored information modules to enable NRM groups to update their plans to include climate change. There is also opportunity to consider developing similar tools for different regions, which goes beyond the NRM focus. This would enable different sectors within a specific region to become better informed about the likely impacts of climate change on their business and to help them proactively plan for adaptation and mitigation 
Lim-Camacho \& Ashworth, Worth a thousand words: Connecting tourism operators with climate change through visualisation techniques

accordingly. Future research in developing similar communication tools should also include an evaluation of the impact on the tool on actual adaptation planning and implementation practices of its end-users to appropriately gauge the benefits of such an approach to communicating about climate change.

\section{REFERENCES}

Ashworth, P. Jeanneret, T., Gardner, J. \& Shaw, H. (2011). Communication and Climate Change: What does the Australian public think? EP112769. Pullenvale: CSIRO.

Becken, S. (2005). Harmonising climate change adaptation and mitigation: The case of tourist resorts in Fiji. Global Environmental Change, 15(4): 381-393.

Bleda, M., \& Shackley, S. (2008). The dynamics of belief in climate change and its risks in business organisations. Ecological Economics, 66(2-3): 517-532.

Bostrom, A., Fischhoff, B. \& Morgan, M.G. (1992). Characterizing mental models of hazardous processes: A methodology and an application to radon. Journal of Social Issues, 48(4), 85-100

Budescu, D. V., Por, H. H., \& Broomell, S. B. (2012). Effective communication of uncertainty in the IPCC reports. Climatic Change, 113(2): 181-200.

Cabrini, L. (2010). Climate change and tourism. In C. Schott (Ed.), Tourism and the Implications of Climate Change: Issues and Actions Vol. 3: 49-64: Emerald Group Publishing Limited.

Clarke, J. M., Whetton, P. H., \& Hennessy, K. J. (2011). Providing application-specific climate projections datasets: CSIRO'S Climate Futures Framework. Paper presented at the MODSIM2011, 19th International Congress on Modelling and Simulation, Perth, Western Australia.

Climate Change Science Program (CCSP) (2009). Best Practice Approaches for Communicating, and Incorporating Scientific Uncertainty in Climate Decision Making. A Report by the Climate Change Science Program and the Subcommittee on Global Change Research. G. Morgan, H. Dowlatabadi, M. Henrionet al. Washington, D.C., National Oceanic and Atmospheric Administration.

de Freitas, C. R. (2003). Tourism climatology: evaluating environmental information for decision making and business planning in the recreation and tourism sector. Int J Biometeorol, 48(1): 45-54.

Department of Resources Energy and Tourism (DRET) (2012). 2020 Tourism Industry Potential: A scenario for growth. Canberra, Commonwealth of Australia.

Devine-Wright, P. (2013). Think global, act local? The relevance of place attachments and place identities in a climate changed world. Global Environmental Change, 23(1): 61-69.

Kahan, D. M. (2010). Fixing the communications failure. Nature, 463(7279): 296-297.

KPMG International (2008). Climate Changes Your Business: KPMG's review of the business risks and economic impacts at sector level: KPMG.

Manzo, K. (2010). Beyond polar bears? Re-envisioning climate change. Meteorological Applications, 17(2): 196-208.

Moser, S. (2010). Communicating climate change: history, challenges, process and future directions. Wiley Interdisciplinary Reviews: Climate Change, 1(1): 31-53.

Nerlich,B, Koteyko, N, \& Brown, B. (2010). Theory and language of climate change communication. Wiley Interdisciplinary Reviews: Climate change. http://onlinelibrary.wiley.com/doi/10.1002/wcc.2/pdf

Nerlich, B., \& Koteyko, N. (2009). Compounds, creativity and complexity in climate change communication: The case of 'carbon indulgences'. Global Environmental Change, 19(3): 345-353.

Nicholson-Cole, S. A. (2005). Representing climate change futures: a critique on the use of images for visual communication. Computers, Environment and Urban Systems, 29(3): 255-273.

Nursery-Bray, M., Pecl, G. T., Frusher, S., Gardner, C., Haward, M., Hobday, A. J., Jennings, S., Punt, A. E., Revill, H., \& van Putten, I. (2012). Communicating climate change: Climate change risk perceptions and rock lobster fishers, Tasmania. Marine Policy, 36(3): 753-759.

Peattie, K., Peattie, S., \& Ponting, C. (2009). Climate change: a social and commercial marketing communications challenge. EuroMed Journal of Business, 4(3): 270-286.

Pidgeon, N. (2012). Climate change risk perception and communication: addressing a critical moment? Risk Anal, 32(6): 951-956.

Sarewitz, D \& Pielke JR, R. (1999). Prediction in science and policy. Technology in Society, 21, 121-133.

Scannell, L., \& Gifford, R. (2013). Personally Relevant Climate Change: The Role of Place Attachment and Local Versus Global Message Framing in Engagement. Environment and Behavior, 45(1): 60-85.

Scott, D., Freitas, C. d., \& Matzarakis, A. (2009). Adaptation in the Tourism and Recreation Sector. In K. L. Ebi, I. Burton, \& G. R. McGregor (Eds.), Biometeorology for Adaptation to Climate Variability and Change, Vol. 1: 171-194: Springer Netherlands.

Thomas, C., Garvey, D., Deslisle, A., \& Gordon, I. (2010). Climate Futures: Preparing Coastal Tourism for Climate Change. Townsville: CSIRO. 